\title{
Transonic-Small-Disturbance and Linear Analyses for the Active Aeroelastic Wing Program
}

\author{
Carol D. Wieseman ${ }^{*}$, Walter A. Silva ${ }^{\dagger}$, Charles V. Spain ${ }^{\ddagger}$, Jennifer Heeg ${ }^{\S}$ \\ NASA Langley Research Center, Hampton, VA 23681
}

\begin{abstract}
Analysis serves many roles in the Active Aeroelastic Wing (AAW) program. It has been employed to ensure safe testing of both a flight vehicle and wind tunnel model, has formulated models for control law design, has provided comparison data for validation of experimental methods and has addressed several analytical research topics. Aeroelastic analyses using mathematical models of both the flight vehicle and the wind tunnel model configurations have been conducted. Static aeroelastic characterizations of the flight vehicle and wind tunnel model have been produced in the transonic regime and at low supersonic Mach numbers. The flight vehicle has been analyzed using linear aerodynamic theory and transonic small disturbance theory. Analyses of the wind-tunnel model were performed using only linear methods. Research efforts conducted through these analyses include defining regions of the test space where transonic effects play an important role and investigating transonic similarity. A comparison of these aeroelastic analyses for the AAW flight vehicle is presented in this paper. Results from a study of transonic similarity are also presented. Data sets from these analyses include pressure distributions, stability and control derivatives, control surface effectiveness, and vehicle deflections.
\end{abstract}

\section{Nomenclature}

$\alpha \quad=$ angle of attack

$C_{L} \quad=$ lift coefficient

$C_{N} \quad=$ normal force coefficient

$C_{p} \quad=$ pressure coefficient

$X=$ transonic similarity parameter

$\Delta C_{p} \quad=$ delta pressure coefficient $=C_{p}$ (lower)- $C_{p}$ (upper)

$\delta$ LEO $=$ leading edge outboard control surface

¿TEO $=$ trailing edge outboard control surface or aileron

\section{Introduction}

The Active Aeroelastic Wing (AAW) program is a cooperative effort among NASA, the Air Force Research Laboratory and the Boeing Company ${ }^{1}$. The program objective is to develop technologies that will allow for the favorable use of aeroelastic properties of a flexible wing aircraft. AAW research has developed and applied highly flexible, actively controlled wing concepts. These concepts utilize traditional aircraft control surfaces such as ailerons and leading edge flaps to twist a flexible wing and thus maneuver the aircraft. The program consists of flight testing, wind tunnel testing and analyses.

Static aeroelastic analyses using mathematical models of both the flight vehicle and the wind tunnel model configurations have been conducted. Linear aerodynamic predictions, although highly successful in the subsonic and supersonic regimes, normally cannot be used to predict transonic aeroelastic behavior accurately. Transonic flow equations capable of modeling flow nonlinearities (shocks, boundary layer, separation, and vorticity) and boundary conditions that induce nonlinear effects (airfoil thickness and shape and large deflections) are required for accurate aerodynamic predictions in the transonic regime. The Computational Aeroelasticity Program- Transonic

\footnotetext{
* Senior Engineer, Aeroelasticity Branch, MS 340, Associate Fellow

† Senior Engineer, Aeroelasticity Branch, MS 340. Associate Fellow

‡ Senior Engineer, Aeroelasticity Branch, MS 340.

${ }^{\S}$ Research Engineer, Aeroelasticity Branch, MS 340, Senior Member AIAA
} 
Small Disturbance code (CAP-TSD) ${ }^{2}$ was developed at the NASA Langley Research Center (LaRC). CAP-TSD is capable of analyzing configurations that have multiple lifting surfaces with control surfaces, bodies, vertical surfaces and a fuselage and solves the TSD equation using an efficient approximation factorization scheme. As implemented for the present study, CAP-TSD is inviscid, so results include the effects of shape and shocks, but not boundary layer, separation or vorticity effects.

The goal of this study was to perform linear and non-linear static aeroelastic analyses of the AAW Flight vehicle. Linear static aeroelastic analyses was conducted with MSC NASTRAN and non-linear static aeroelastic analyses was performed using CAP-TSD. Static aeroelastic characterizations of the flight vehicle were produced in the transonic regime and at low supersonic Mach numbers. Research efforts conducted through these analyses include defining regions of the test space where transonic effects play an important role and investigating transonic similarity. Included are a few comparisons with flight test data.

The NASTRAN results include the effects of compressibility, surface twist and surface camber for the complete flight vehicle configuration. The CAP-TSD results are for only a wing and tip launcher configuration. Linear CAPTSD includes the effects of compressibility, surface twist and surface camber. Nonlinear CAP-TSD, in addition to the effects included in linear CAP-TSD, includes the effects of shocks.

\section{Linear Aeroelastic Analyses}

The Boeing Aircraft Company furnished the AAW Flight Vehicle Finite Element Model (FEM) that was used for the MSC NASTRAN linear structural and aeroelastic analysis described in this paper. Figure 1 presents an image of the structural model.
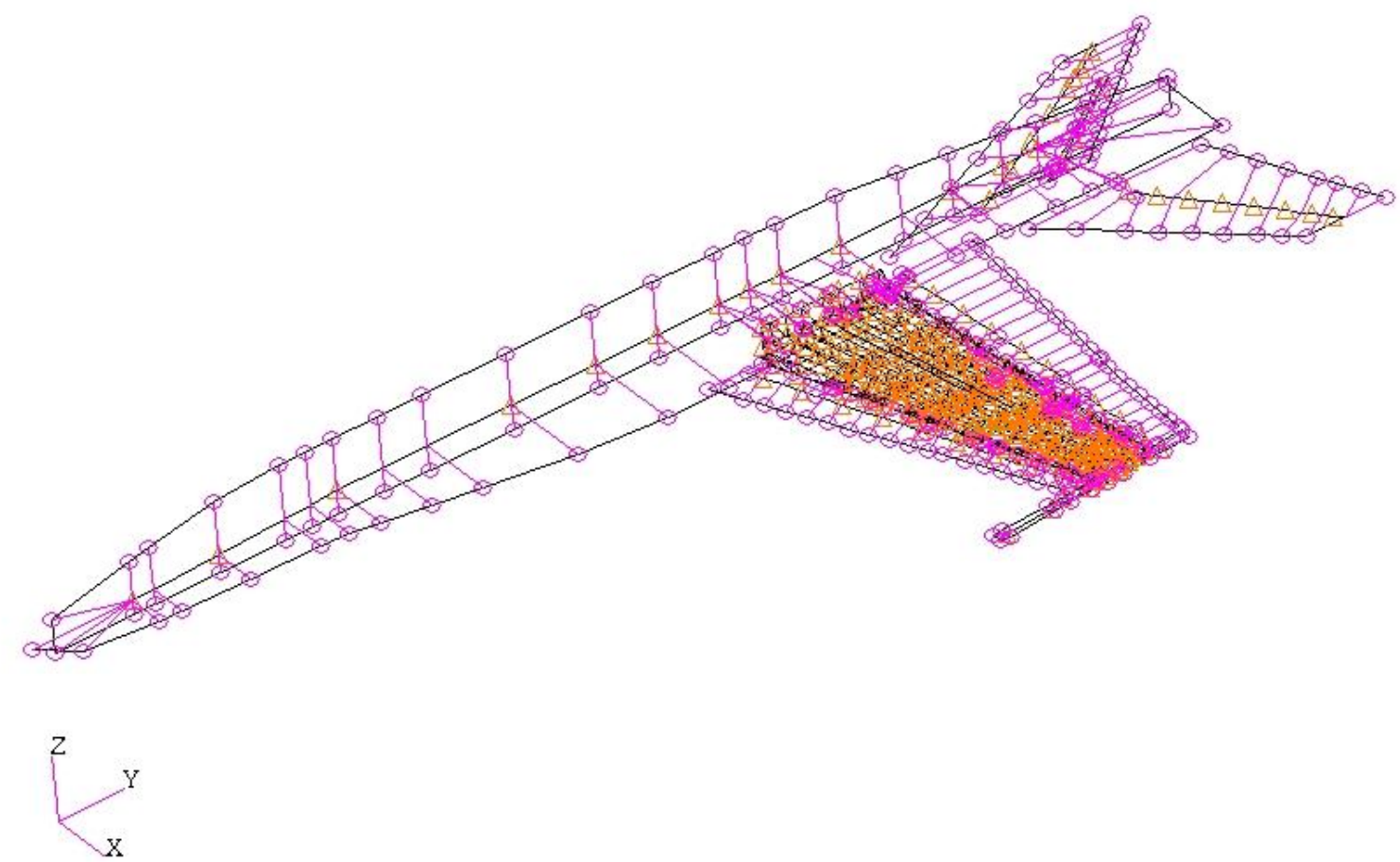

Figure 1. Structural Finite Element Model of the AAW Flight Vehicle.

Although the FEM was furnished as a left-hand semi-span model, the assumption of symmetry applies when comparing the NASTRAN aeroelastic results to the CAP-TSD aeroelastic results, generated from a right-handed semispan model. The FEM contains no true representation of the actual materials and structure as some FEMs do, but rather is a mathematically derived model which has been demonstrated to possess the correct overall geometry, stiffness and mass of the AAW flight vehicle. This FEM was also the basis for the AAW wind-tunnel model design, development and analysis performed at LaRC.

Linear static aeroelastic analyses were performed using MSC NASTRAN ${ }^{3}$. At subsonic conditions, a doublet lattice $^{4}$ aerodynamic model was employed. ZONA51 ${ }^{5}$ aerodynamic computations were performed at supersonic 
conditions. Figure 2 shows the aerodynamic layout used for both of these aerodynamic codes. Shown are the fuselage modeled as a flat plate, the wing, tip launcher, horizontal tail and vertical tail. It includes four control surfaces: two leading-edge control surfaces and two trailing-edge control surfaces. The aerodynamic boxes representing the control surfaces are shown in the figure as red- leading edge inboard, blue- leading edge outboard, green- trailing edge inboard, and gold- trailing edge outboard (aileron). The model contains 858 aerodynamic boxes. All NASTRAN output of stability and control derivatives and differential pressure coefficients presented are based on static aeroelastic trim solutions. Wing twist and camber were modeled using direct matrix input of the downwashes into NASTRAN ${ }^{3}$.



Figure 2. NASTRAN aerodynamic paneling for flight vehicle

\section{Non-Linear Aeroelastic Analyses}

\section{Computational Procedures}

The CAP-TSD code is a finite difference program that solves the general-frequency modified transonic small disturbance (TSD) potential equation ${ }^{2}$. This equation is solved by a time-accurate approximate factorization algorithm. The equations of motion for the structural dynamics are incorporated into the aeroelastic solution through interpolation of the vibration mode shapes. The aeroelastic equations of motion are written in a form such that they can be integrated with respect to time. For dynamic aeroelastic analysis, two steps are required to perform the calculations. The steady-state flow field is calculated to account for wing thickness, camber, mean angle of attack and static aeroelastic deformation. Thus, the starting flow field for the dynamic aeroelastic analysis is provided. In the case of the active aeroelastic wing, the primary interest lies in computation of the static aeroelastic solution.

The CAP-TSD computational model consists of a half-span wing-only model with a vertical plane of symmetry used for symmetric analyses. A launcher rail is included at the wing tip. The inboard portion of the wing extends to the aircraft centerline and there is no representation of the fuselage and tail surfaces.

The grid dimensions for the model are $122 \times 83 \times 81$ in the $\mathrm{x}, \mathrm{y}$ and z-directions, respectively, for a total of 820,206 grid points. The grid extends 6 root chords upstream, 7 root chords downstream, 2.6 semispan lengths in the y-direction and 6 root chords in both the positive and negative z-directions.

Figure 3 shows part of the grid used in the CAP-TSD analyses. Only the grid details in the vicinity of the wing are shown. The wing border is shown in green. 


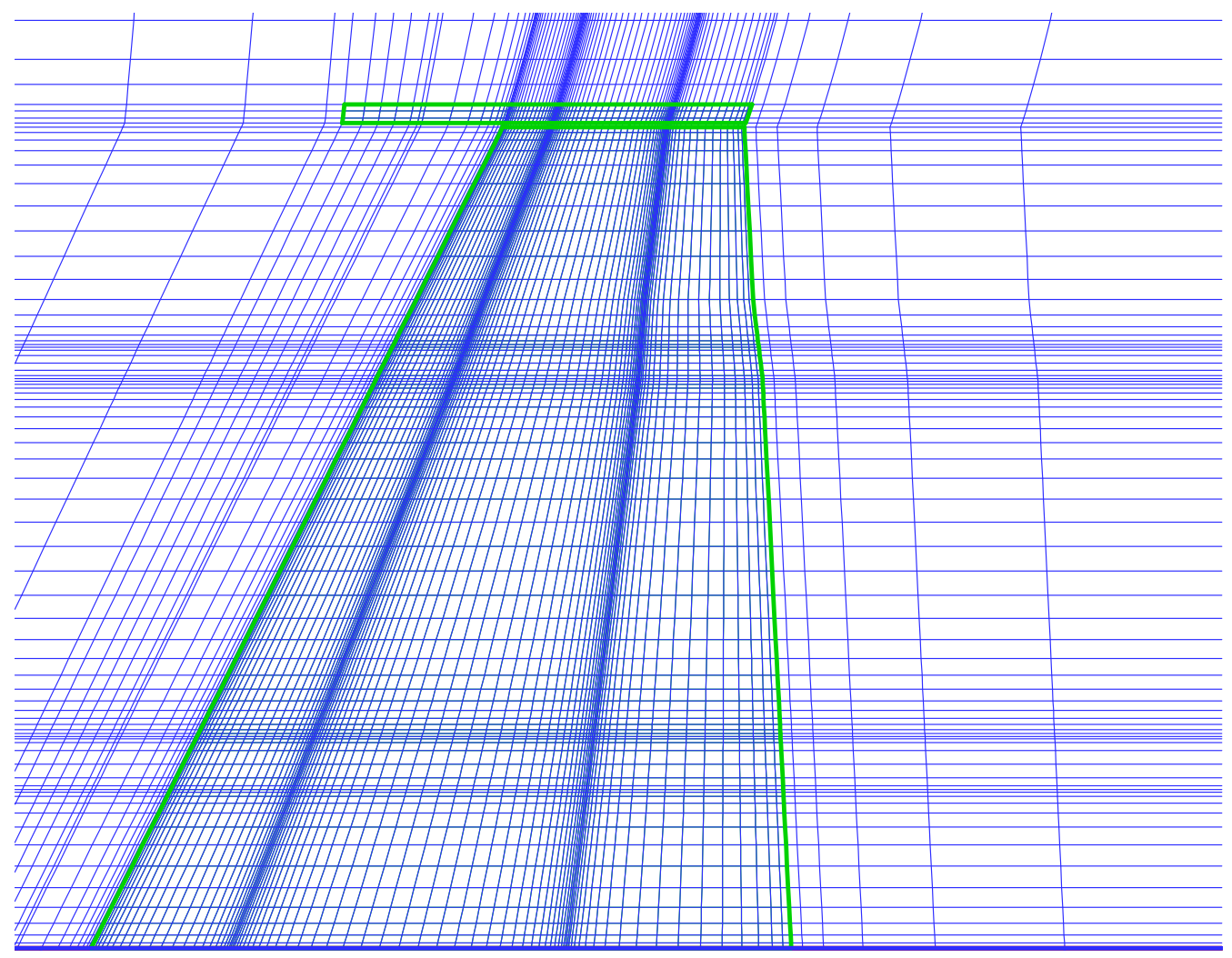

Figure 3. Portion of the Grid for CAP-TSD analyses showing details in region of the wing.

Splining the modeshapes proved challenging for this configuration because of the wing fold and other discontinuities. A method using Matlab ${ }^{6}$ was devised to spline the modeshapes. A convergence study was performed to determine how many flexible modes would be required for performing an aeroelastic analyses. A total of forty-seven flexible modes were calculated from a NASTRAN modal analysis of the flight vehicle. Results were computed at Mach 0.95, 5000 feet and one degree angle of attack with all 47 modes, the lowest 10 flexible modes, and lowest 20 flexible modes. This flight condition was chosen because it is a difficult case at transonic conditions and high dynamic pressure. Figure 4 shows a comparison of the lift coefficients due to angle of attack for three different cases. The results show that twenty modes are sufficient for modal convergence. The CAP-TSD results presented in this paper used twenty modes. 


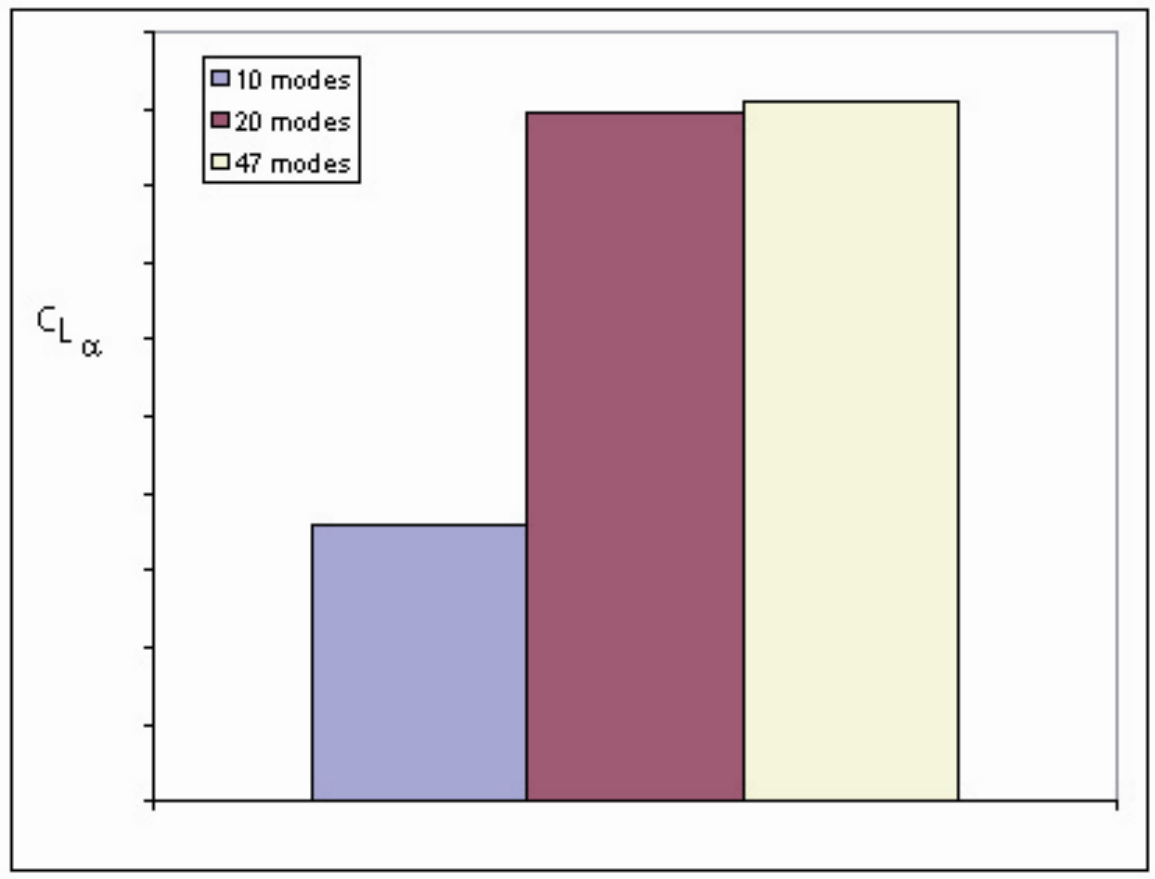

Figure 4. Lift curve slope for modal convergence study

Solutions were computed over a range of angles of attack from -1.5 to 1.5 degrees in 0.5 degree increments and control surface deflections ranging from -1.5 to 1.5 degrees in 0.5 degree increments in order to obtain stability and control derivatives. This paper will present results of stability and control derivatives, converged wing deflection shapes and the corresponding pressure distributions using the NASTRAN method and the linear and nonlinear CAPTSD methods.

\section{Results}

The static aeroelastic solutions were calculated over a range of Mach numbers and dynamic pressures corresponding to the flight test and wind-tunnel test conditions. These conditions are shown in figure 5. Results will be presented for linear NASTRAN analyses and both linear and non-linear CAP-TSD analyses. Results will be shown for stability and control derivatives, wing static deflection shapes, and corresponding static pressure distributions. The linear CAP-TSD analyses were performed only at 5000 feet and 10000 feet altitudes. The purpose of performing these analyses was to identify regions in the flight envelope where nonlinear effects became significant. 


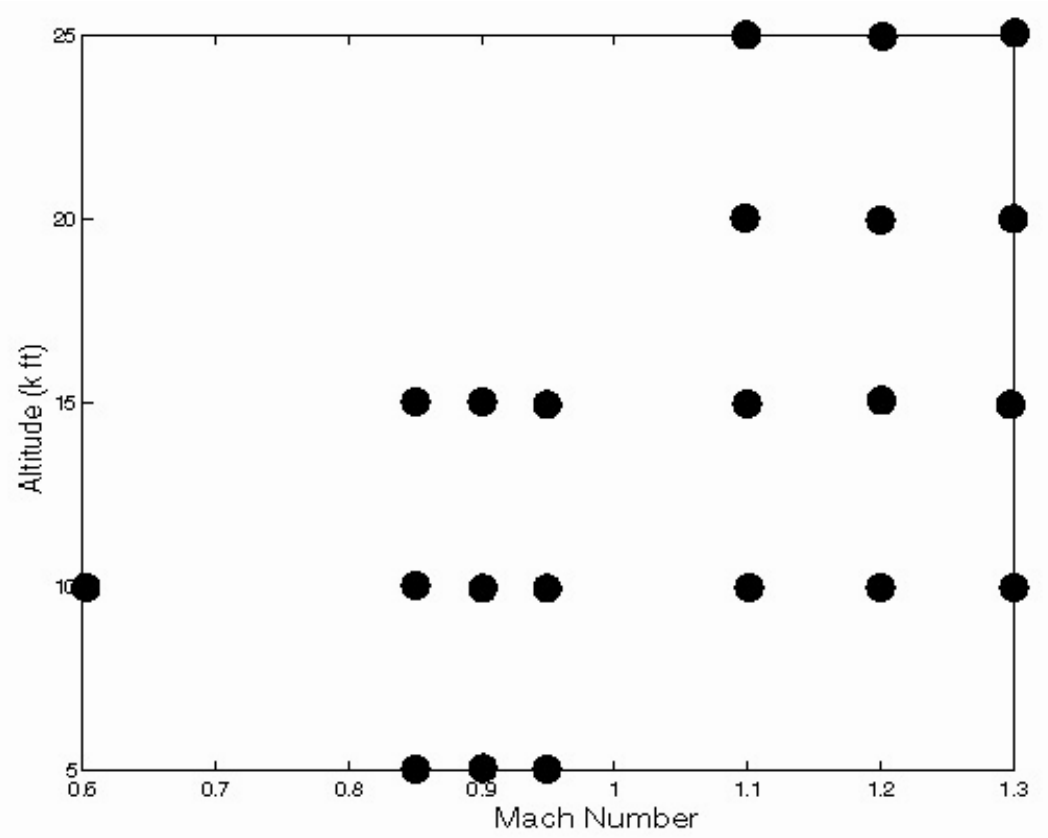

Figure 5. Flight test conditions corresponding to Analyses cases that were run.

\section{A. Stability and Control Derivatives}

Linear (NASTRAN) and non-linear CAP-TSD results were calculated for five different altitudes ranging from 5000 to 25000 feet. Lift and moment coefficient derivatives were calculated for angle of attack and all four control surfaces: leading edge inboard and outboard, trailing edge inboard and outboard (aileron). Results are presented for the lift derivatives due to angle of attack and due to leading edge outboard and aileron.

For clarity, results will be compared in the groups shown in Table 1.

Table 1. Stability and Control Derivatives to be compared

\begin{tabular}{|c|c|c|}
\hline Results & Altitude (1000 ft) & Figure \\
\hline NASTRAN linear analyses & $5,10,15,20,25$ & 6 \\
\hline $\begin{array}{l}\text { NASTRAN linear and CAP-TSD linear } \\
\text { analyses }\end{array}$ & 5 and 10 & 7 \\
\hline CAP-TSD linear and non-linear analyses & 5 and 10 & 8 \\
\hline CAP-TSD nonlinear analyses & $5,10,15,20,25$ & 9 \\
\hline $\begin{array}{l}\text { Flight test, NASTRAN and CAP-TSD } \\
\text { nonlinear analyses }\end{array}$ & 10 & 10 \\
\hline
\end{tabular}

Figure 6 shows a comparison of selected stability and control derivatives. The NASTRAN linear analyses were performed on the full flight vehicle which includes horizontal tail, fuselage and vertical tail. Each of the curves in figure 6 corresponds to a different altitude, as shown in the legend. The only results presented are for the lift coefficient derivatives due to angle of attack, leading edge outboard control surface and aileron control surface.

The combined effect of Mach number and altitude are clearly seen. At a specific Mach number the altitude effect also corresponds to an effect of dynamic pressure. The effect of altitude is greater for the supersonic conditions than for the subsonic conditions. The lift coefficient due to angle of attack increases in the supersonic region with decreased altitude due to aeroelastic reshaping. The lift coefficient due to angle of attack increases with increasing decreasing altitude. The lift coefficient due to leading edge control surface decreases with increasing Mach number into the transonic region and then increases again with supersonic Mach numbers. The lift coefficient due to leading edge outboard control surface decreases with decreasing altitude which corresponds to an increase in dynamic pressure. Based on the actual values of the data (negative) the leading edge control surface actually increases in effectiveness. The aileron control surface effectiveness shown by lift coefficient due to aileron (trailing 
edge outboard control surface) decreases in the transonic region until it actually reverses at approximately Mach 0.9 at 5000 feet. The control surface effectiveness decreases with decreasing altitude.

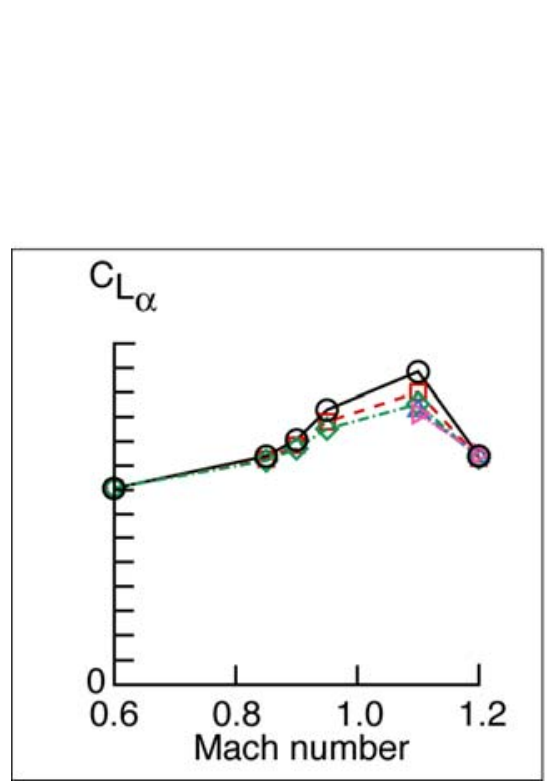

a) Lift coefficient due to angle of attack

$$
\begin{aligned}
& -5 \mathrm{k} \mathrm{ft} \\
& -\backsim-.10 \mathrm{kft} \\
& -\diamond-15 \mathrm{k} \mathrm{ft} \\
& -\triangle-\cdot 20 \mathrm{k} \mathrm{ft} \\
& \rightarrow-25 \mathrm{k} \mathrm{ft}
\end{aligned}
$$

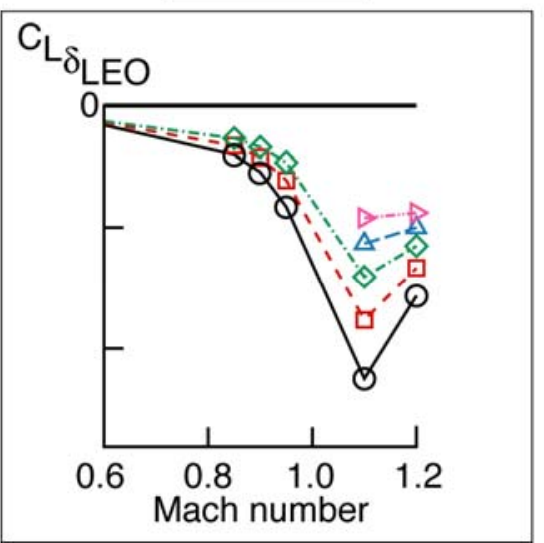
b) Lift coefficient due to Leading Edge outboard control surface

c) Lift coefficient due to trailing edge outboard control surface (aileron)

Figure 6. Linear (NASTRAN) stability and control derivatives.

Linear CAP-TSD results were generated for selected conditions to evaluate when the inclusion of non-linear effects becomes necessary. First a comparison is made of both NASTRAN and linear CAP-TSD shown in figure 7. Two sets of data are shown on the plots. The first indicated by circles and squares are the NASTRAN results which include the entire flight vehicle. The second set indicated by diamonds and triangles are the linear CAP-TSD results for the wing and launcher only. As expected, the same trends are shown for both linear methods. The magnitudes are different because this is a comparison of two different configurations. 


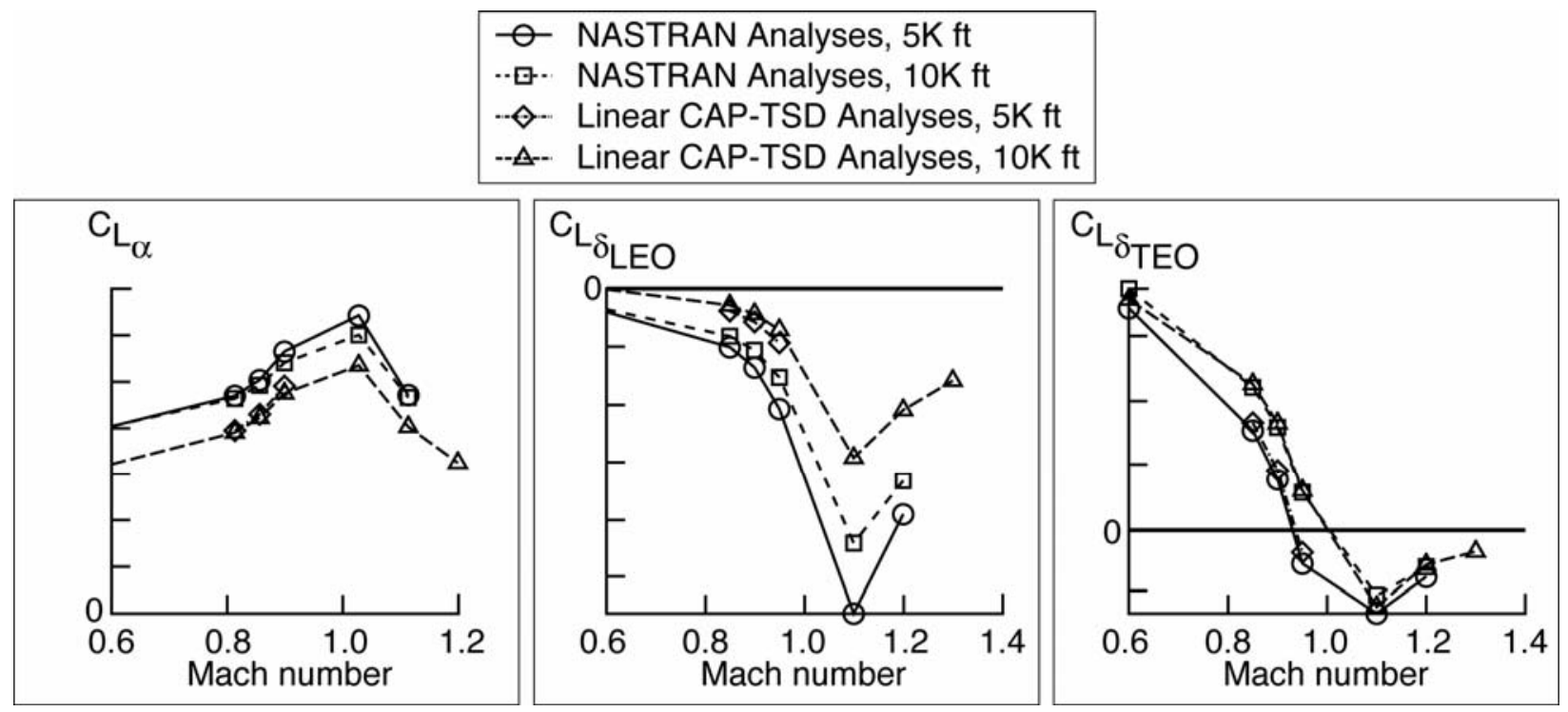

a) Lift coefficient due to angle of attack b) Lift coefficient due to Leading Edge outboard control surface c) Lift coefficient due to trailing edge outboard control surface (aileron)

Figure 7. Comparison of Linear (NASTRAN) and linear CAP-TSD stability and control derivatives.

A comparison of linear and non-linear CAP-TSD results is presented in figure 8 for two different altitudes: 5000 and 10000 feet. The linear CAP-TSD results are shown with diamonds and triangles. The nonlinear CAPTSD results are shown with circles and squares. All three stability and control derivatives show that at Mach 0.6, the linear and non-linear methods yield identical results indicating that at this condition the assumption of linear flow conditions is appropriate. At supersonic conditions, the values of the coefficients approach each other, as well, approaching a region of linear behavior. These figures show that for the AAW it is necessary to include the effects of non-linear aerodynamics early in the design and analysis process for the range of Mach numbers indicated.

\begin{tabular}{|ll|}
$-\vartheta$ & Non-Linear Analyses, $5 \mathrm{~K} \mathrm{ft}$ \\
$-\bullet-$ & Non-Linear Analyses, $10 \mathrm{~K} \mathrm{ft}$ \\
$-\diamond$ & Linear CAP-TSD Analyses, $5 \mathrm{~K} \mathrm{ft}$ \\
$-\triangle$ & Linear CAP-TSD Analyses, $10 \mathrm{~K} \mathrm{ft}$ \\
\hline
\end{tabular}

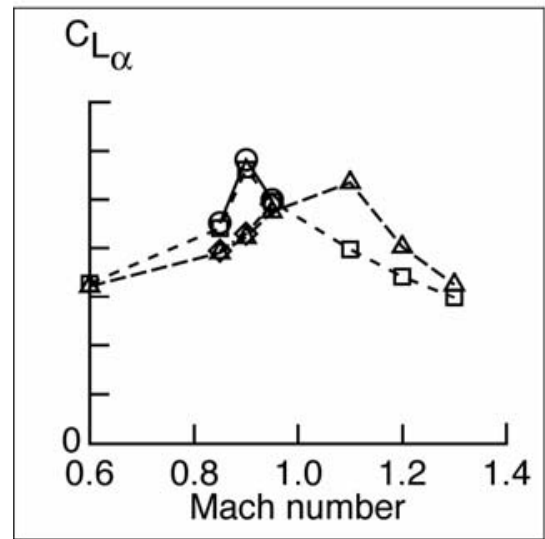

a) Lift coefficient due to angle of attack

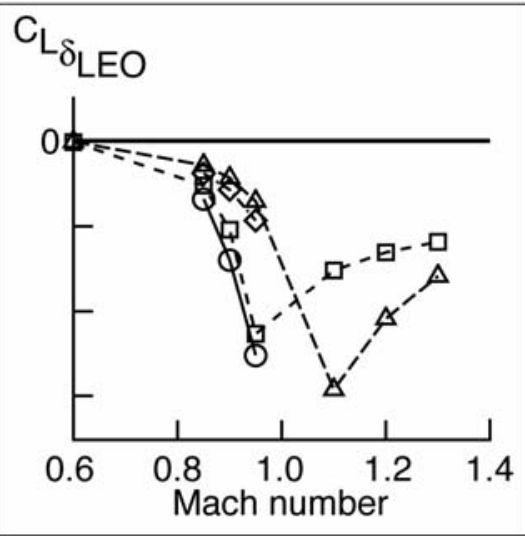

b) Lift coefficient due to Leading Edge outboard control surface

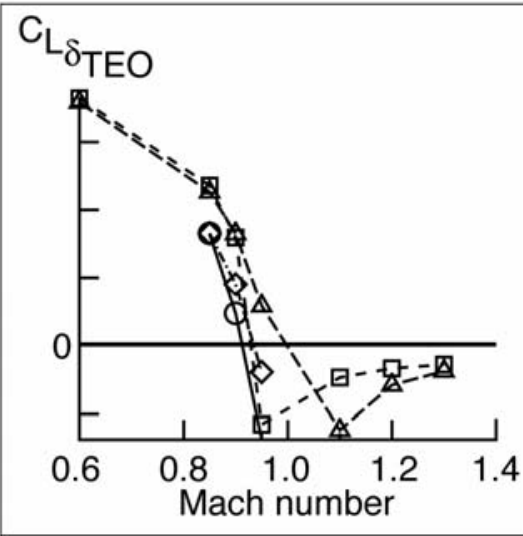

c) Lift coefficient due to trailing edge outboard control surface (aileron)

Figure 8. Comparison of linear (NASTRAN) stability and control derivatives with linear CAP-TSD results. 8 
The non-linear stability and control results are shown in figure 9 at all 5 altitudes. The lift coefficient due to angle of attack is less sensitive to altitude than the linear results. The values peak in the transonic region at approximately Mach 0.9. The leading edge outboard effectiveness increases in the transonic region and then decreases in the supersonic region. The lift coefficient due to aileron decreases at transonic conditions.

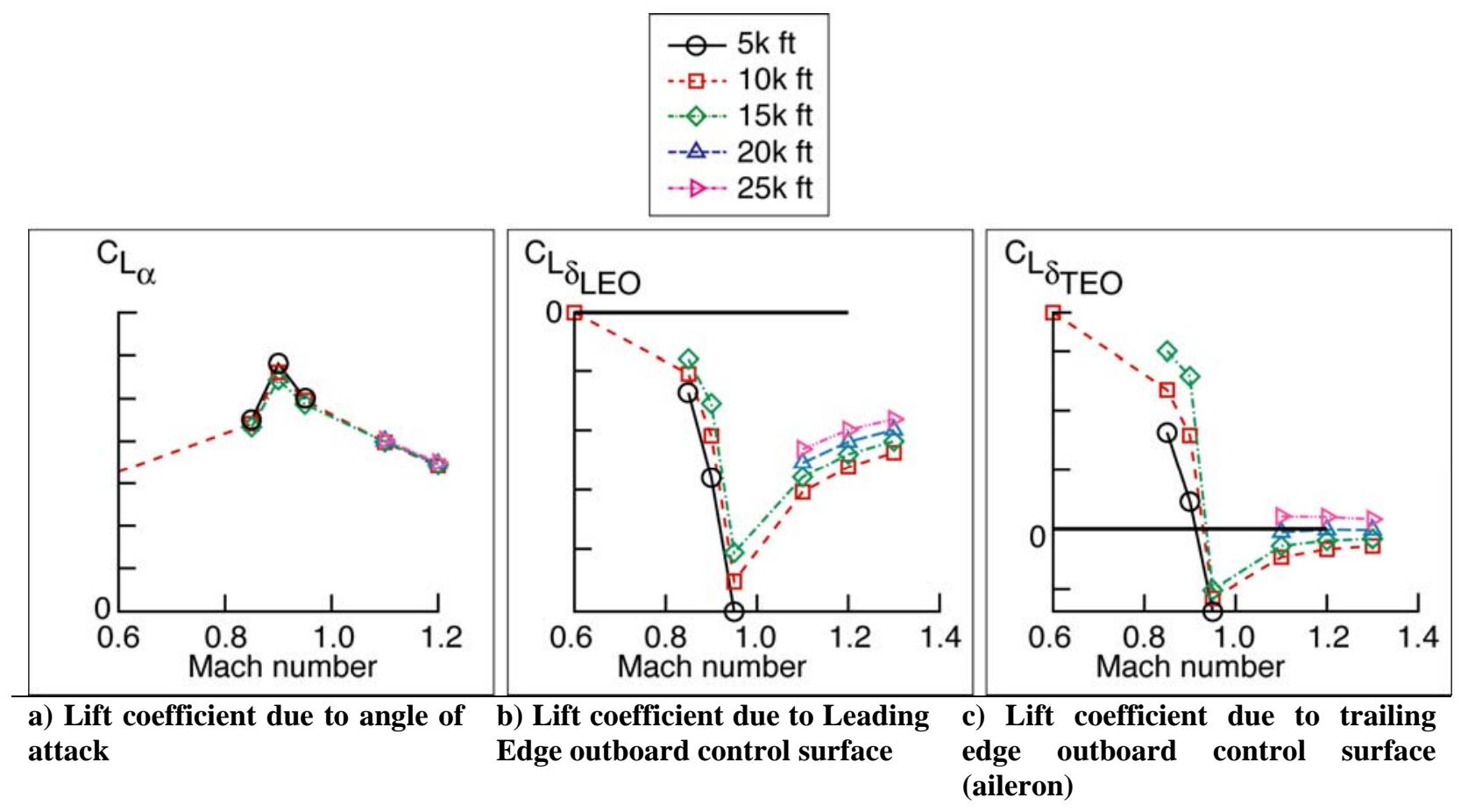

Figure 9. Non-linear CAP-TSD Stability and control derivatives.

The stability and control derivatives for linear NASTRAN, nonlinear CAP-TSD and flight test are compared at $10000 \mathrm{ft}$ altitude in figure 10. Three sets of data are included in each plot. The first set of data, indicated by the solid circle symbols, represent the flight test data. The second set of data, represented by the square symbols, are the nonlinear CAP-TSD analyses. The third set of data, represented by the diamonds, are the linear NASTRAN results.

Evaluation of $C_{L \alpha}$ (shown in figure 10a) is difficult because this derivative may be significantly influenced by the fuselage and tail sections which are not represented in the CAP-TSD model. However, the trend of the CAPTSD data indicates that $C_{L \alpha}$ peaks in magnitude at Mach 0.9 as does the experimental data. NASTRAN predicts the peak values at about Mach 1.1. The lift coefficient due to angle of attack shows that the trend of the nonlinear analyses at transonic conditions is closer to the flight test data than the linear analyses.

For the outboard wing control surfaces, comparisons of the derivatives should be reasonable because the surfaces are well removed from the fuselage. The leading edge control surface effectiveness shows similar trends between the linear NASTRAN and nonlinear CAP-TSD analyses with the results comparing reasonably well with the flight test. At the supersonic condition, the flight test data lies between linear NASTRAN and non-linear CAPTSD results. Neither set of analytical results captures the behavior of the flight test data. However, NASTRAN predicts an extremely low value at Mach 1.1, whereas the low value predicted by CAP-TSD is at Mach 0.95.

For the trailing edge control surface effectiveness, the trends are very similar between linear, nonlinear and the flight test despite differences in the models. All three sets of data predict a tendency toward reversal at this altitude. Again we see the CAP-TSD low value at Mach 0.95 with the NASTRAN low value at Mach 1.1. In addition, the effects of boundary layer and flow separation are not captured with this version of CAP-TSD 

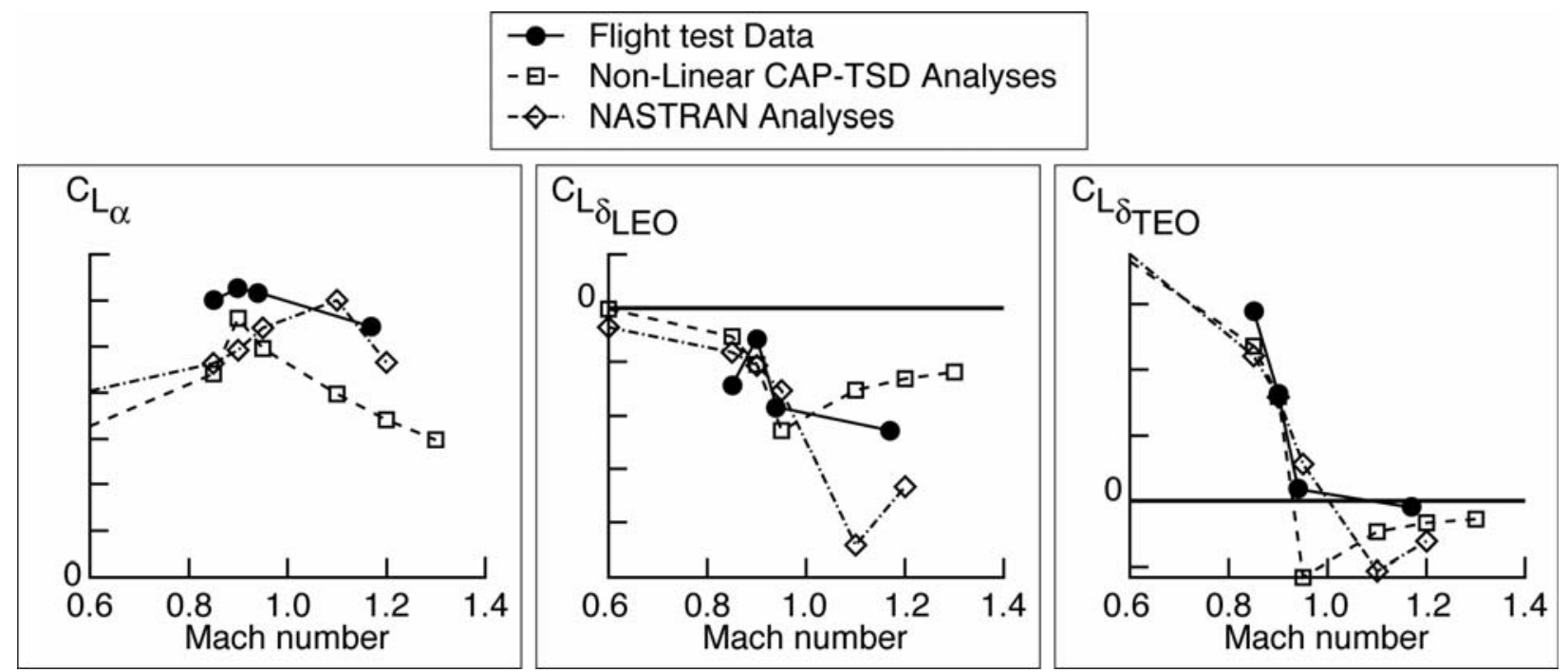

\section{a) Lift coefficient due to angle of} attack

\section{b) Lift coefficient due to Leading} Edge outboard control surface c) Lift coefficient due to trailing edge outboard control surface (aileron)

Figure 10. Comparison of Flight test, NASTRAN and non-linear CAPTSD stability and control derivatives for 10000 feet

\section{B. Static Deflection Shapes and Corresponding static Pressures}

The derivatives described above give some insight as to how well the linear and nonlinear codes represent the behavior of the flight vehicle from about Mach 0.85 to 1.3. This issue is also discussed by Heeg, etal. ${ }^{7}$ with approximately the same observations. The predicted static deflection shapes and corresponding wing pressure distributions provide additional insight. Two flight conditions are examined: Mach 0.85, 10000 feet and an angle of attack of 1 degree and Mach 1.1 at 10000 feet at an angle of attack of 0 degrees. The wing pressure distributions shown in all the figures are the delta pressure coefficients which are the lower minus the upper pressure coefficients. For comparison all of the contour levels are identical for a given flight condition.

Figure 11 shows the aeroelastic shape for the NASTRAN linear results and the corresponding pressure distribution. The deflection shape shown in figure 11a is predominately wing bending with some wing twist leading edge down with most of the deformation at the leading edge outboard control surface. The corresponding pressure distribution is shown in figure 11b. Although the model incorporated the entire flight vehicle only the pressures on the wing and launcher are shown.

The deflection shape and the corresponding pressures are shown for linear CAP-TSD in figure 12 . The deflection shape shows predominantly bend down with most of the bending at outboard of the wing fold. There is also some wing twist at the outboard section. The corresponding pressure distribution in figure $12 \mathrm{~b}$ shows some local phenomenon but is very similar to the linear NASTRAN results shown in figure 11b. 


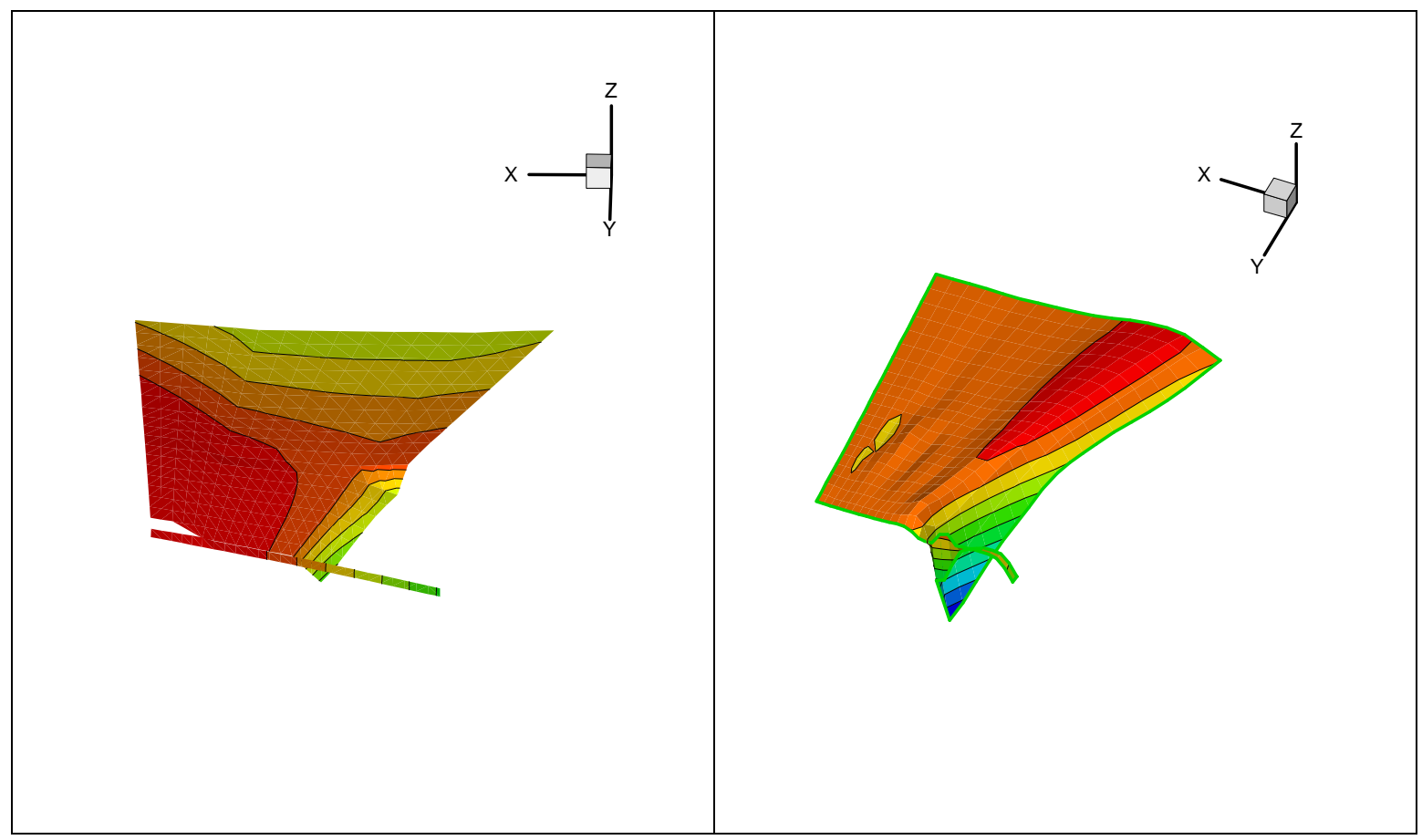

a) Deflection Shape

b) Pressure Distribution

Figure 11. Deflection and pressure distributions from NASTRAN linear analyses for $M=.85, \alpha=1$ degree, 10000 feet.

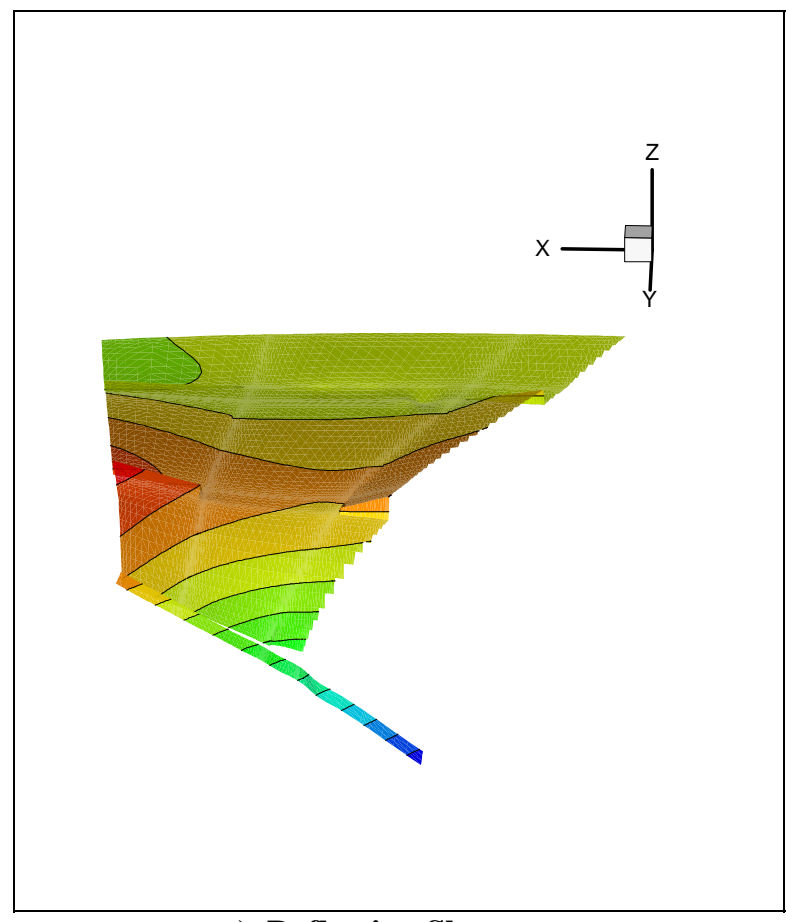

a) Deflection Shape

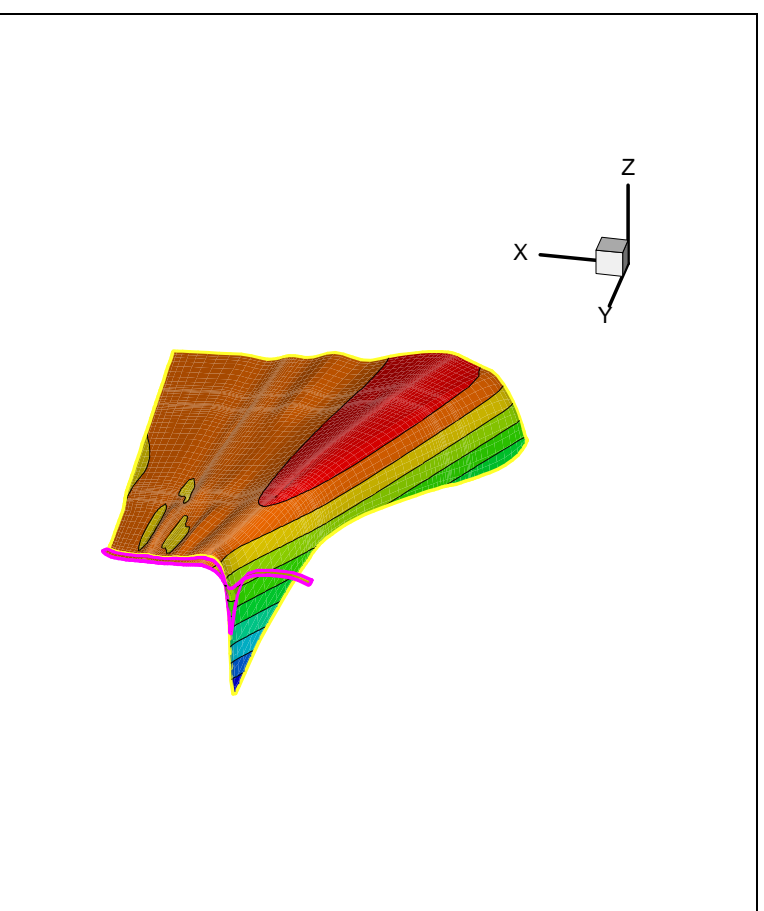

b) Pressure Distribution

Figure 12. Deflection and pressure distributions from CAP-TSD linear analyses for $M=.85, \alpha=1$ degree, 10000 feet. 
The deflection shape and the corresponding pressures are shown in figure 13 for the CAP-TSD non-linear method. The deflection shape shows almost identical deflection shape to linear CAP-TSD results. The corresponding pressure distribution in figure 13b shows some local phenomenon but is basically very similar to the linear results shown in figure 12b and 11b. At this Mach number, a shock has not yet formed.

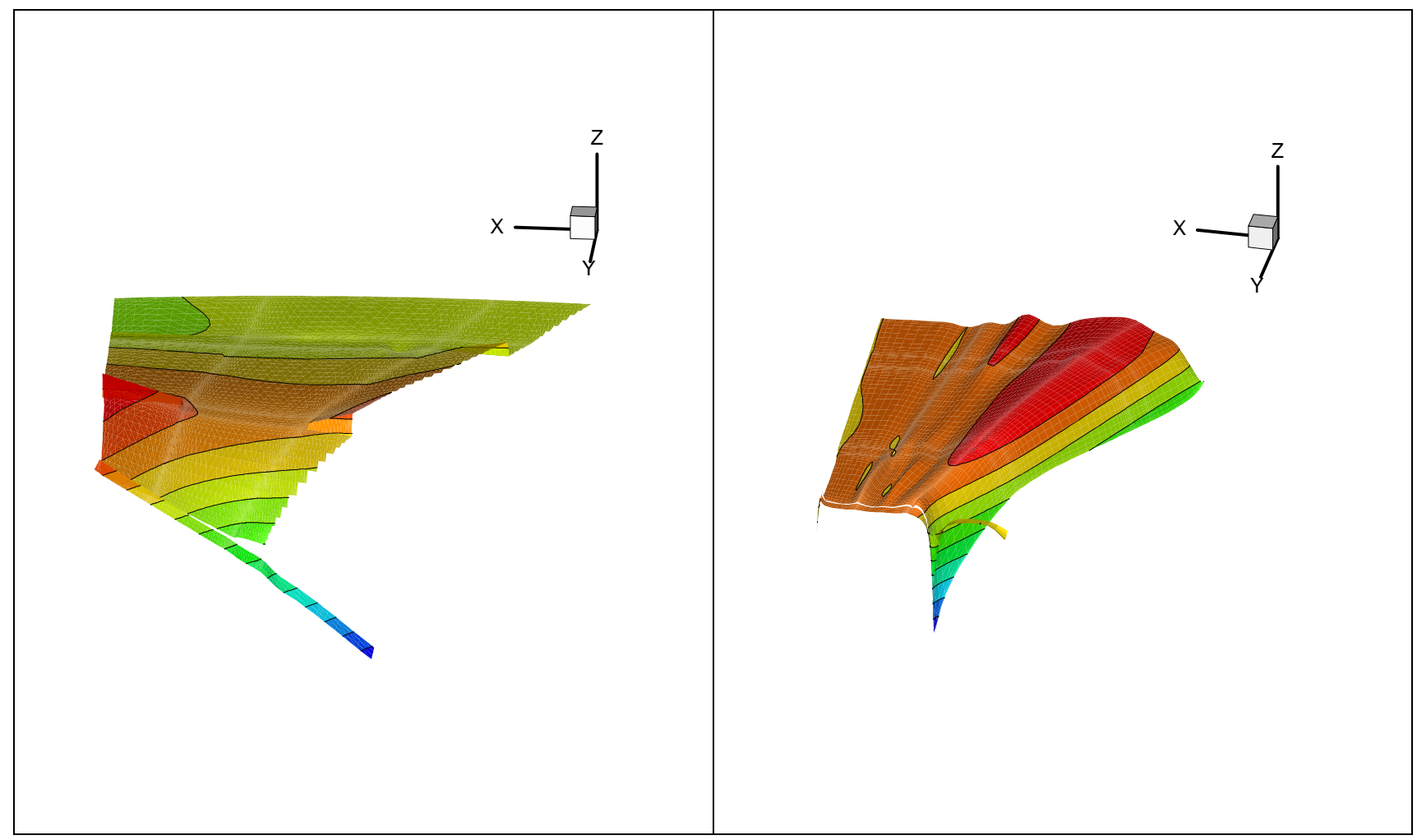

a) Deflection Shape

b) Pressure Distribution

Figure 13. Deflection and pressure distribution from CAP-TSD nonlinear analyses for $M=0.85, \alpha=1$ degree, 10000 feet.

The results for a supersonic case at Mach 1.1, 10000 feet altitude, and an angle of attack of 0 degrees are presented in figures 14-16. Figure 14 shows the aeroelastic shape for the NASTRAN linear results and the corresponding pressure distribution (using ZONE51 theory). The deflection shape shown in figure 14a has some wing bending down and some nose-down wing twist. The corresponding pressure distribution is shown in figure 14b.

The deflection shape and the corresponding pressures are shown in figure 15 for the CAP-TSD linear method. The deflection shape shows bend down and twist down at the outboard. The corresponding pressure distribution in figure 15b shows some local phenomenon but is very similar to the linear results shown in figure 14b.

The deflection shape and the corresponding pressures are shown for non-linear CAP-TSD in figure 16. The deflection shape shows predominantly bend down. The magnitudes of the deflection are substantially less than the linear deflections. The corresponding pressure distribution in figure $16 \mathrm{~b}$ shows some local phenomenon but is very similar to the linear results shown in figure 15b. At Mach 1.1 linear theory (NASTRAN ZONA51 and CAP-TSD linear) predict much stronger leading-edge pressures than nonlinear CAP-TSD. Based on the derivatives presented previously, the lower non-linear pressures predicted by nonlinear CAP-TSD are more representative of the experimental data. 


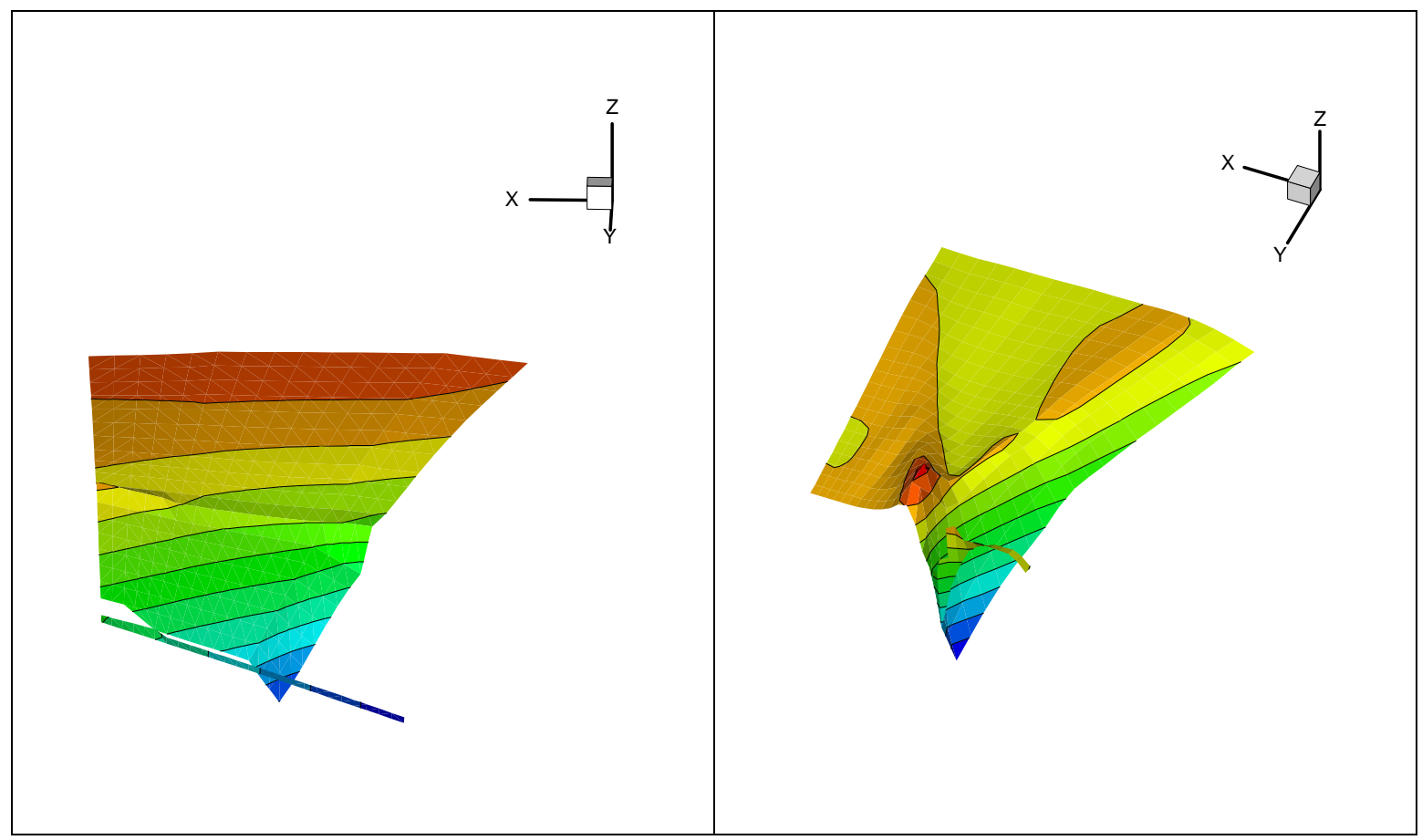

a) Deflection shape

b) Pressure Distribution

Figure 14. Deflection and pressure distribution from NASTRAN linear analyses for $M=1.1, \alpha=0$ degrees, 10000 feet.

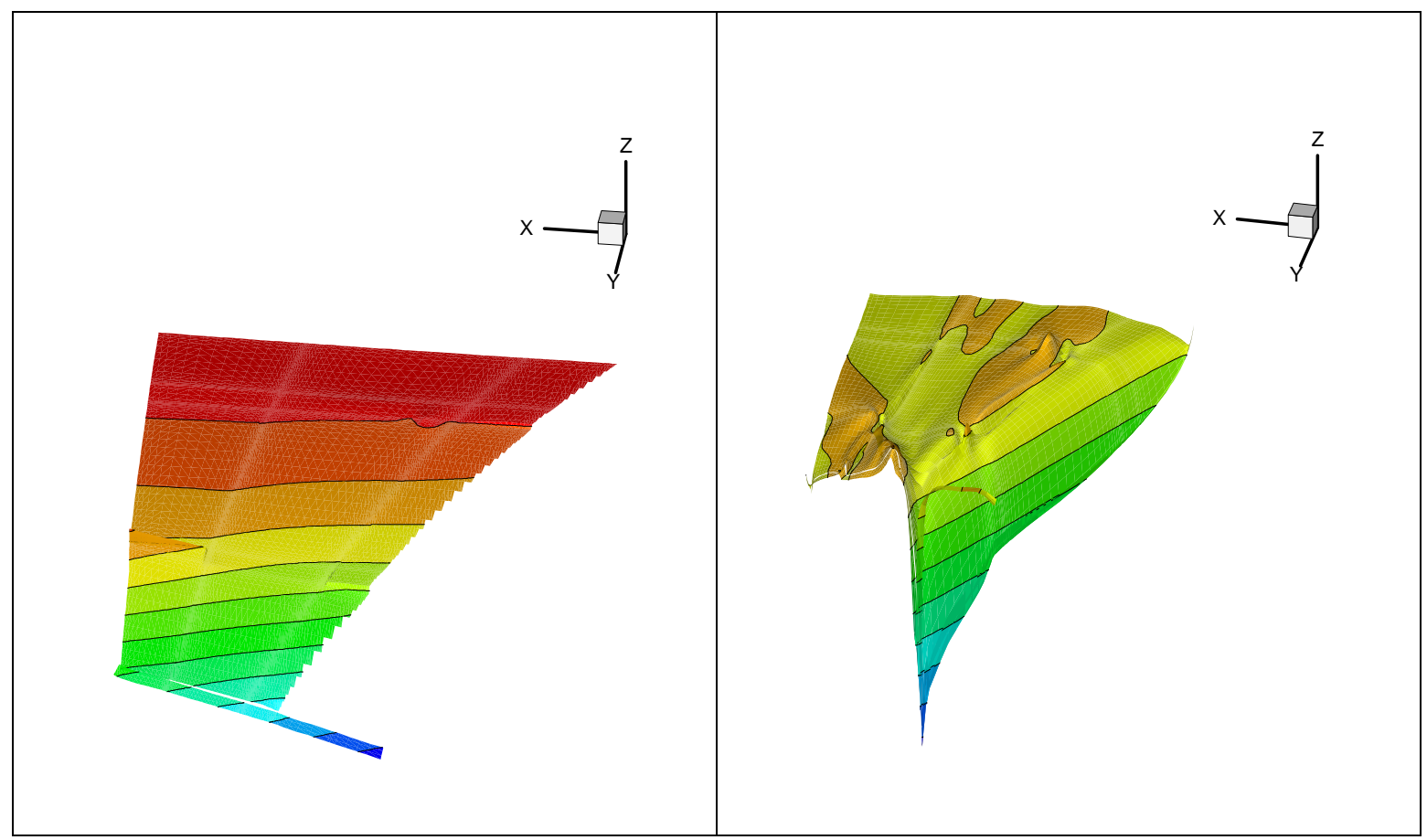

a) Deflection Shape

b) Pressure Distribution

Figure 15. Deflection and pressure distribution from CAP-TSD linear analyses for $M=1.1, \alpha=0$ degrees, 10000 feet. 




a) Deflection Shape

b) Pressure Distribution

Figure 16. Deflection and pressure distribution from CAP-TSD nonlinear analyses for $M=1.1, \alpha=0$ degrees, 10000 feet.

\section{Transonic Similarity}

An important part of the AAW program is the comparison of flight test data and wind tunnel test data. This required design, and fabrication of a scaled wind tunnel model, tested at scaled conditions. The dynamic pressure was scaled based on static aeroelastic similarity considerations; the Mach number was scaled based on transonic similarity ${ }^{8}{ }^{9}$ requirements.

Compressible, inviscid, small disturbance potential flow equations indicate that the shock location and strength for identical Mach numbers will be different in gases due to differences in ratios of specific heat, $\gamma$. In the case of the AAW program, the flight test data was acquired in air, $\gamma=1.4$, while the wind tunnel test data was acquired in R134a, $\gamma=1.11$. To maintain similarity of the pressure distributions, the Mach number is adjusted such that the transonic similarity parameter, $X$, is maintained. The definition of the transonic similarity parameter is shown in equation 1.

$X=\frac{1-M_{\infty}^{2}}{\left(M_{\infty}^{2}(\gamma+1)\right)^{2 / 3}}$

It should be kept in mind that as viscous effects become more dominant in the flow field of an experiment, this similarity requirement becomes less valid because it is based on inviscid flow equations.

The wind tunnel test Mach numbers were determined by applying the transonic similarity condition. Table 2 shows the transonically similar Mach numbers for test data to be acquired in the wind tunnel test medium, R134a. 
Table 2 Transonically similar Mach numbers for Air and R134a

\begin{tabular}{|l|l|}
\hline Nominal condition & Transonically Similar Condition \\
\hline$\gamma=1.4$ & $\gamma=1.11$ \\
\hline Mach number in Air & Mach number in R134a \\
\hline 0.6 & 0.621 \\
\hline 0.85 & 0.861 \\
\hline 0.89 & 0.898 \\
\hline 0.9 & 0.907 \\
\hline 0.95 & 0.954 \\
\hline 1.1 & 1.091 \\
\hline 1.15 & 1.137 \\
\hline 1.2 & 1.182 \\
\hline
\end{tabular}

The projected impact on the resulting pressure distributions was examined utilizing two different approaches. The first was a purely analytical approach using CAP-TSD analyses of the flight vehicle. The second was using experimental wind-tunnel test data.

The analytical results are described first. Analyses were performed at the nominal test Mach numbers using the properties of air and R134a and at the transonically similar Mach numbers in R134A. The upper and lower surface static aeroelastic pressures are shown in figure 16 for one wing semispan location. The first set of data are shown in red for a nominal Mach number of 0.9 and an angle of attack of 2 degrees. It is clear that at this Mach number, there is mixed flow resulting in a shock on the upper surface of the wing at approximately $65 \%$ chord. The red line indicates pressure distribution for Mach 0.9 in air. The solid black line corresponds to Mach 0.9 in R134A. Using the same Mach number in heavy gas results in a weaker shock that is forward at approximately $60 \%$ chord. If the Mach number in R134A is increased to the transonically similar Mach number of 0.907 the shock moves aft and becomes stronger and more closely approximates the pressure distribution of Mach 0.9 in air. These results show clearly the need for using transonic similarity to obtain matched pressure distributions.

The normal coefficients for these cases are shown in figure 17. Two distinct sets of data are provided at these conditions. The first set, on the left sid of the plot, contains results from rigid analyses. The results for the transonically similar conditions - air at Mach 0.9 and R134A at Mach 0.907 - are identical. B y contrast the results for matched Mach numbers - air at Mach 0.9 and R134A at Mach 0.9 - are significantly different. Because the results are for a rigid vehicle, they demonstrate the isolated impact of maintaining transonic similarity.

Shown at the right of figure 17 are aeroelastic results for the flexible vehicle which give the combined impact of transonic similarity and dynamic pressure effect. The figures show that improved loads and pressure distributions are achieved using transonically similar Mach numbers. 
$M=.907, A O A=2 \mathrm{deg}, \mathrm{R} 134 \mathrm{~A}$

$M=.9, A O A=2 \operatorname{deg}, R 134 A$

$M=.9, A O A=2 \mathrm{deg}$, Air
Solid - Upper Surface

Dashed - Lower Surface

$42 \%$ wing semispan

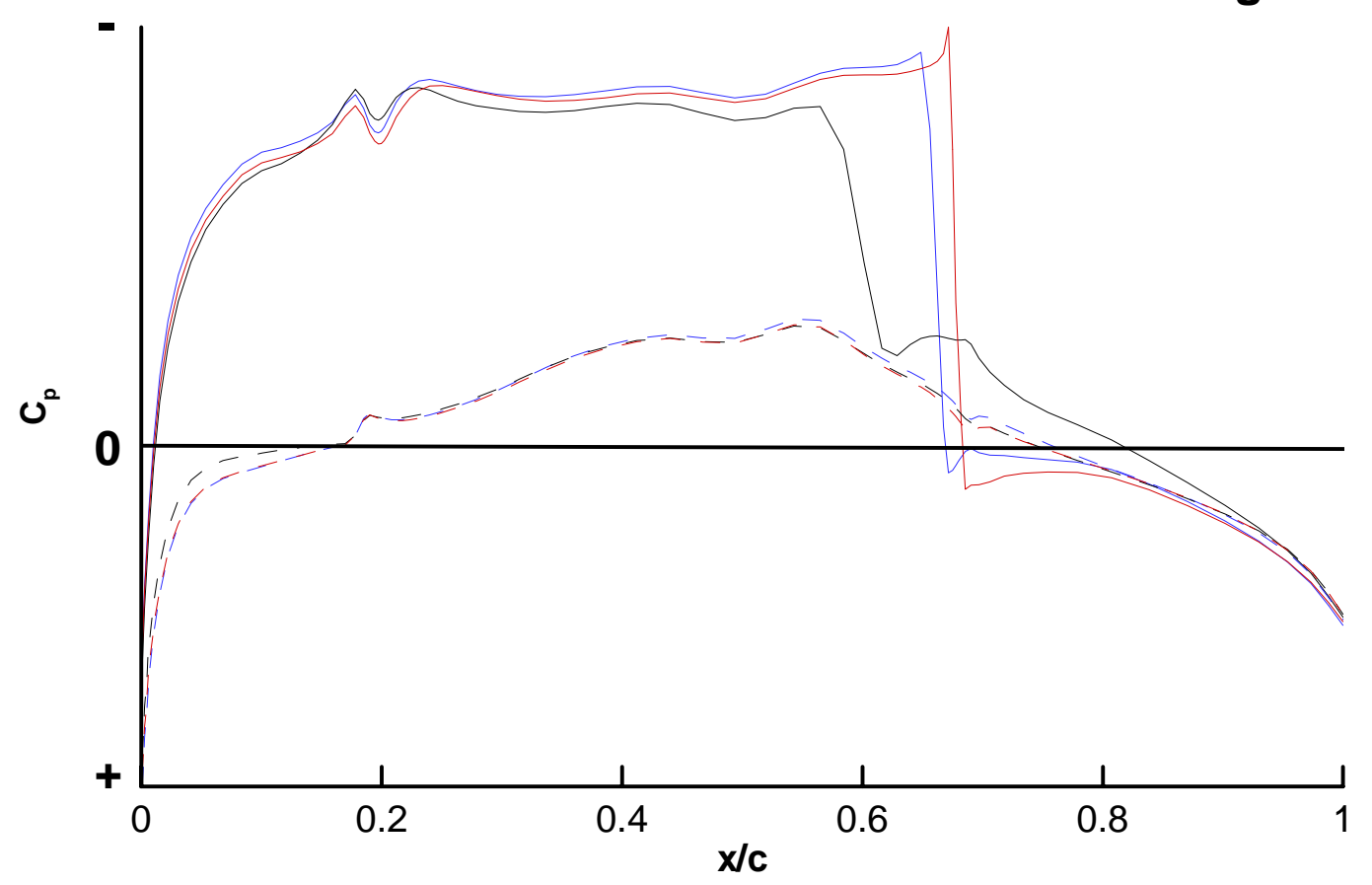

Figure 16. Comparison of chordwise pressure distributions.

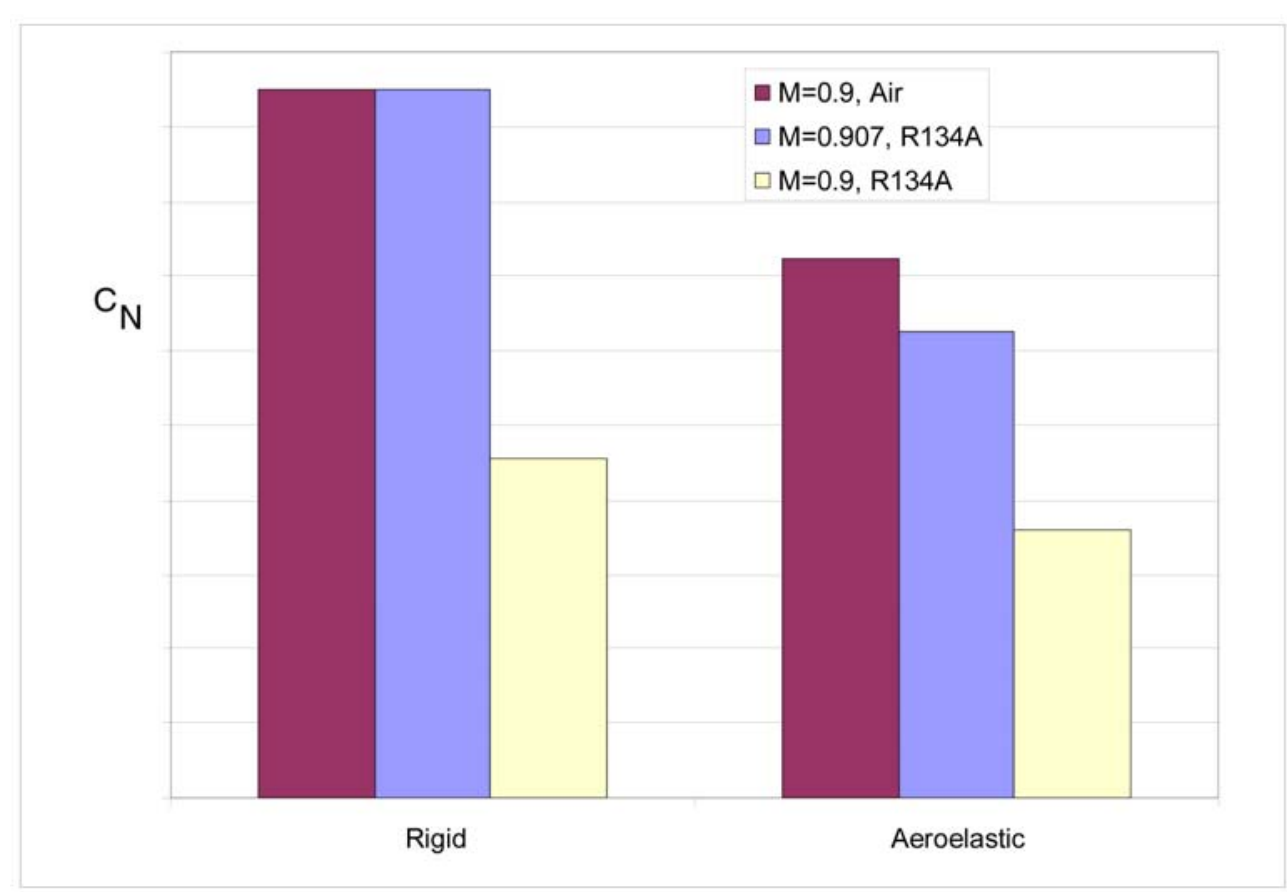

Figure 17. Comparison of normal coefficients. 
A second illustration of transonic similarity was produced using experimental wind tunnel test data at a slightly lower Mach number. The wind-tunnel test condition in air was Mach 0.890 . The transonically similar condition was Mach 0.898 in R134.

The goal was to be able to test at these conditions an angle of attack of 2 degrees. The actual measured conditions are shown in table 3.

Table 3. Measured test conditions for experimental transonic similarity comparison.

\begin{tabular}{|c|c|c|c|}
\hline $\begin{array}{c}\text { Mach Number } \\
\text { (goal) }\end{array}$ & $\begin{array}{c}\text { Dynamic } \\
\text { Pressure } \\
\text { (psf) }\end{array}$ & $\begin{array}{c}\text { Angle of } \\
\text { Attack } \\
\text { (deg) }\end{array}$ & $\begin{array}{c}\text { Test } \\
\text { Medium }\end{array}$ \\
\hline $0.888(0.89)$ & 200.03 & 2.02 & Air \\
\hline $0.890(0.89)$ & 202.53 & 2.02 & R134A \\
\hline $0.901(0.90)$ & 202.50 & 2.01 & R134A \\
\hline
\end{tabular}

Figure 18 shows the measured upper and lower surface experimental pressure coefficients at two wing semispan locations: $87 \%$ and $42 \%$. On each plot, solid connecting lines indicate upper surface pressures, while dashed connecting lines indicate lower surface pressures. The three different conditions are shown using different colors and line styles, as indicated in the legend.

The air condition at Mach 0.89 is shown with the black circles. As indicated in the figure there is a weak shock on the upper surface at approximately $35-40 \%$ chord for the $87 \%$ wing span location. Testing at approximately the same Mach number in R134A, the shock moves forward and becomes weaker. Increasing the Mach number in R134A to the transonically similar Mach number of 0.90 returns the shock to the aft chord location. The pressure distributions for the transonically similar Mach numbers are very similar, although there is an almost constant offset in magnitude. The reason for this offset is unknown and is undergoing further study.

Equivalent Mach numbers in both media produce almost identical pressure distributions over $60 \%$ of the chord. The chordwise pressure distribution for transonically similar Mach numbers differ more from each other than the pressure distributions for the equivalent Mach number over this wing section.

The experimental results do not present as straightforward an example of the importance of maintaining transonic similarity as shown by the analytical results. Potential reasons and issues with the experimental data are pressure sensor accuracy, lack of smoothness of the airfoil, hinge line discontinuities, and test conditions that cannot be matched exactly. These sources of discrepancy make it difficult to assess transonic similarity at these conditions.

The measured normal coefficients at these test conditions are provided in figure 19. These clearly show that using transonically similar conditions results in improved loads correlation. 


\section{$M=0.89$, Air \\ $M=0.89, R 134 A$ \\ $M=0.90, R 134 A$}

Solid - Upper Surface Dashed - Lower Surface

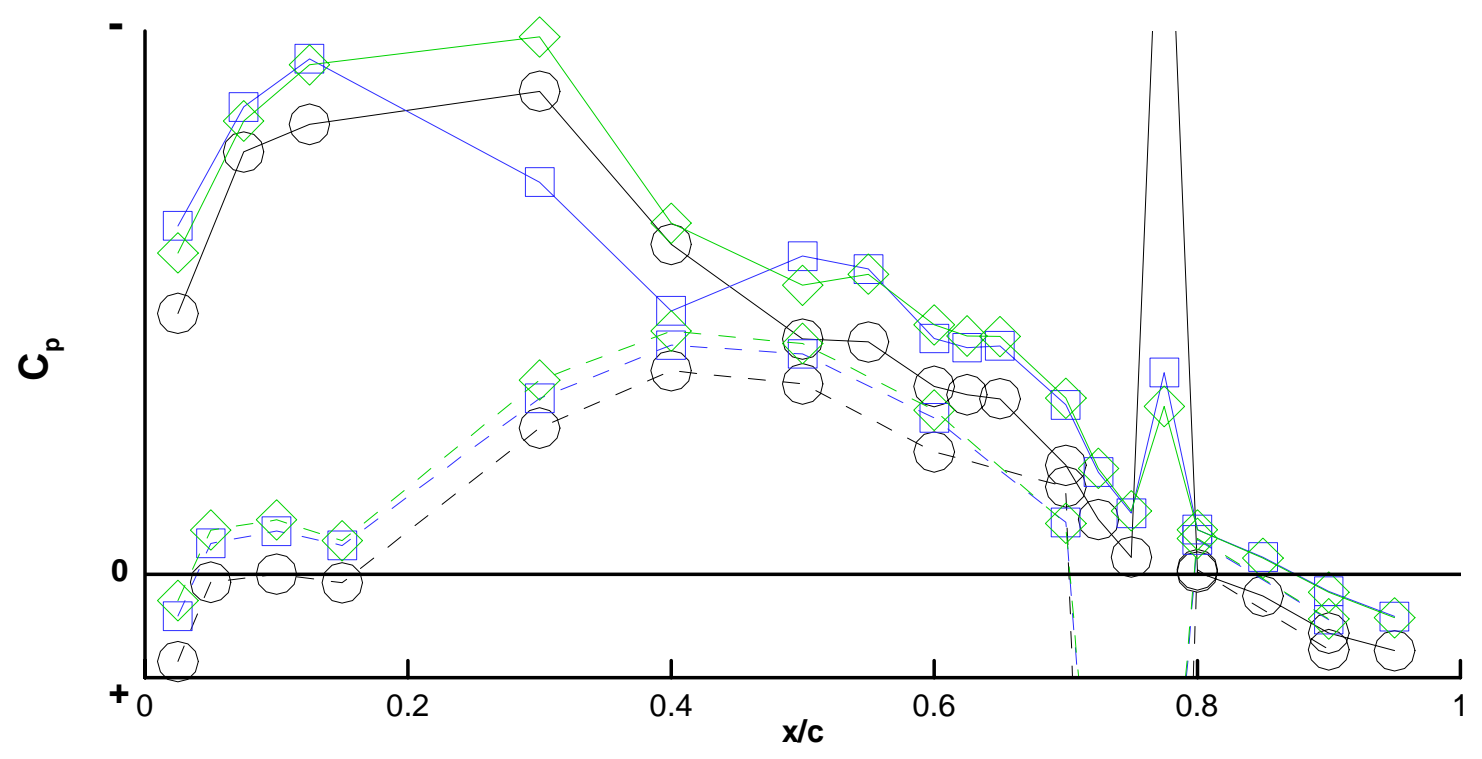

a) $87 \%$ wing semispan

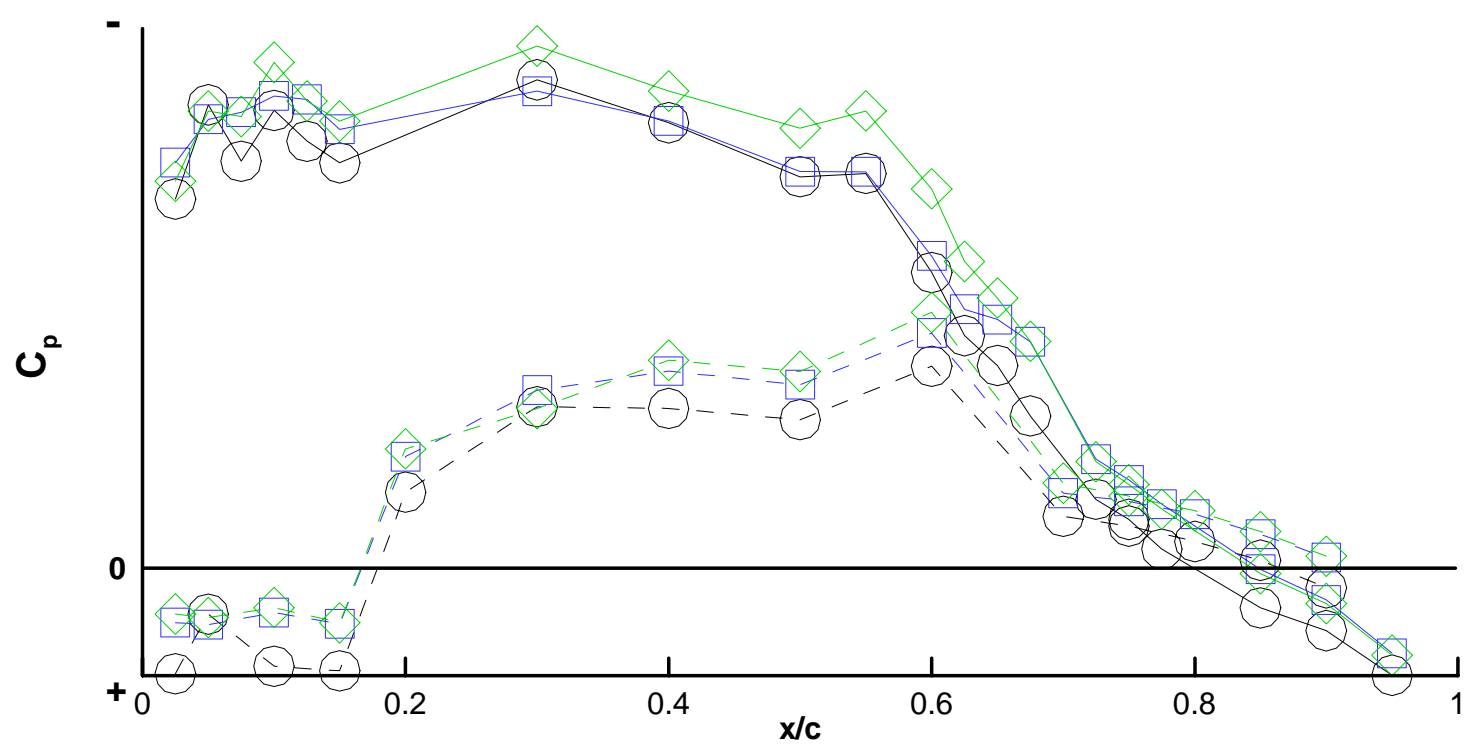

b) $42 \%$ wing semispan

Figure 18. Upper and lower surface pressure distributions for transonically similar conditions. 


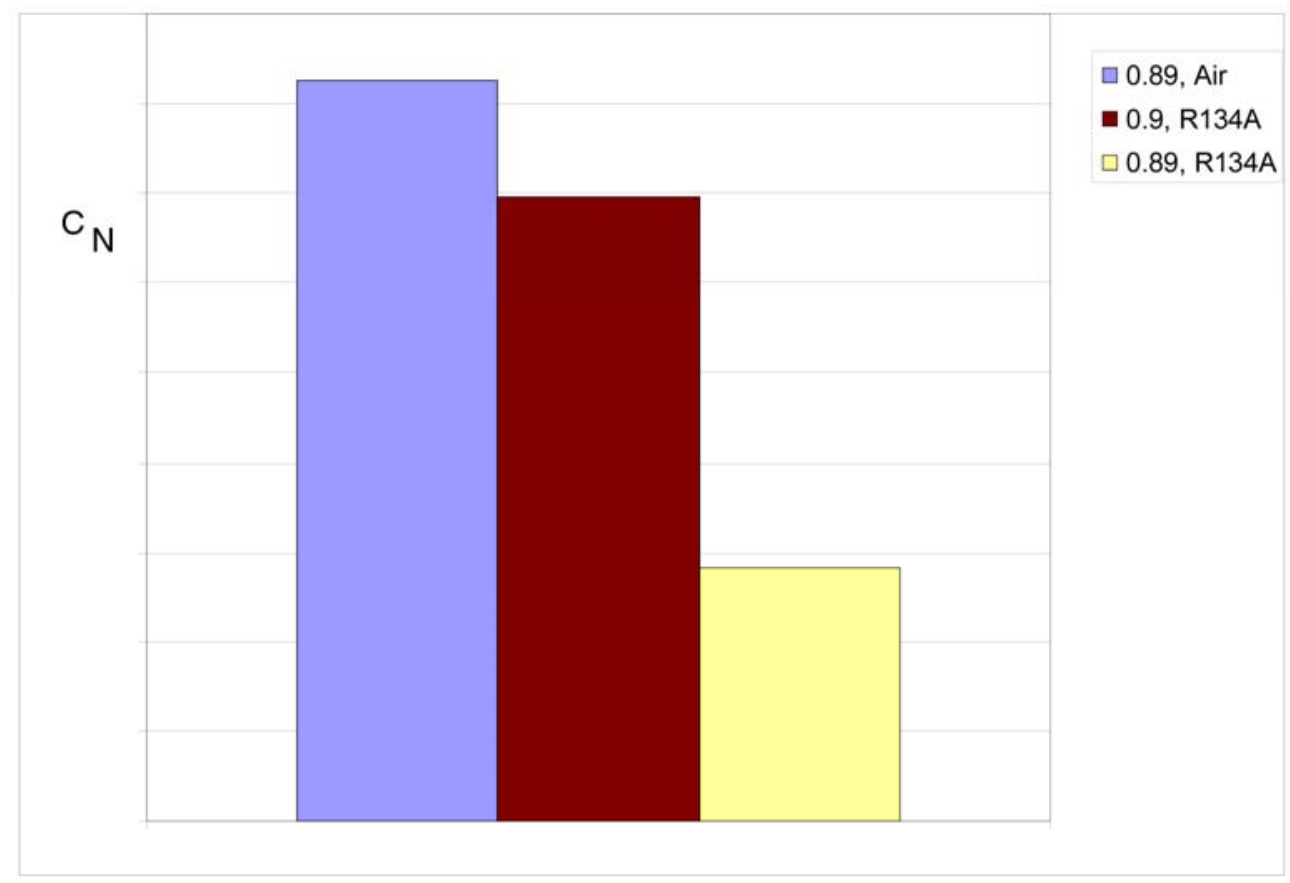

Figure 19. Normal Force coefficient for the wind-tunnel data

\section{Concluding Remarks}

The goal of this paper was to present results of linear and non-linear aeroelastic analyses of the AAW Flight vehicle in support of the AAW flight test program. The main reason was to determine when non-linear analyses are required and linear analyses are insufficient. This paper has presented results and comparisons of stability and control derivatives, pressure distributions and aeroelastic shapes for flight test conditions in the subsonic and low supersonic ranges with variations in dynamic pressure. The analyses and comparisons with experimental data have shown that linear analysis is helpful but inadequate for transonic conditions studied in the AAW program. The nonlinear CAP-TSD, even for a simplified configuration, improves the predictions. Further analyses with full configurations and even higher-order aeroelastic codes along with additional wind-tunnel data reduction may be desirable.

\section{References}

\footnotetext{
${ }^{1}$ Pendleton, E. W., Bessette, D., Field, P.B., Miller, G. D., and Griffin, K.E., “Active aeroelastic wing flight research program and model analytical development," AIAA Journal of Aircraft, Vol 37, No. 4, July-August 2000.

${ }^{2}$ Batina, John T., "Efficient Algorithm for Solution of the Unsteady Transonic Small-Disturbance Equation," Journal of Aircraft, Vol. 25, No. 7, 1988, pp. 598-605.

${ }^{3}$ Rodden, William P. and Johnson, Erwin H. :MSC/NASTRAN Aeroelastic Analysis Users Guide, Version 68, October 1994, The MacNeal-Schwendler Corporation.

${ }^{4}$ Giesing, J.P., Kalman, T. P. , Rodden, W. P. “Subsonic unsteady aerodynamics for general configurations”. AIAA Paper 1972-26 Aerospace Sciences Meeting, 10th, San Diego, Calif., Jan. 17-19, 1972

${ }^{5}$ Chen, P.C. and Liu, D.D., "A Harmonic Gradient Method for Unsteady Supersonic Flow Calculations," Journal of Aircraft, Vol. 2, No. 5, May 1985, p. 371-379.
} 
${ }^{6}$ MATLAB : the language of technical computing. Using MATLAB., Natick, MA: MathWorks, c2000

${ }^{7}$ Heeg, Jennifer; Spain, Charles V., Florance, James R., Wieseman, Carol D., Ivanco, Thomas G., DeMoss, Joshua A., and Silva, Walter A, Experimental Results from the Active Aeroelastic Wing Wind Tunnel Program, AIAA2005-2234, 46th AIAA/ASME/ASCE/AHS/ASC Structures, Structural Dynamics \& Materials Conference, 2005

${ }^{8}$ Anders, J.B and Anderson, W.K. and Murthy, A.V, "Transonic Similarity Theory Applied to a Supercritical Airfoil in Heavy Gas,” Journal of Aircraft, Vol. 35, No. 6, 1999, pp. 957-964.

${ }^{9}$ Busemann, Adolf, “Application of Transonic Similarity”, NACA TN 2687, April 1952. 